\title{
Metabolic Disorders in Patients with Chronic Kidney Failure
}

\author{
R. CIBULKA, J. RACEK \\ Institute of Clinical Biochemistry and Hematology, Charles University, Faculty of Medicine and \\ Faculty Hospital in Pilsen, Czech Republic \\ Received September 26, 2006 \\ Accepted January 10, 2007 \\ On-line available February 8, 2007
}

\begin{abstract}
Summary
This review article summarizes the problems of metabolic disorders and nutrition imbalances that often occur in chronic kidney failure $(\mathrm{CKF})$ or following regular dialysis treatment. In this survey, we cover the pathogenesis of these disorders, their clinical consequences, and their association with the most severe complications of chronic kidney failure and dialysis treatment. These complications are primarily atherosclerosis, malnutrition, anemia, hyperparathyroidism, and other serious problems that markedly and negatively affect prognosis and the quality of life of uremic patients. Risk factors for cardiovascular disease are discussed in-depth because cardiovascular disease is the leading cause of death in patients with chronic kidney failure. It is important to pay attention to the development of these complications because early diagnosis and therapy can improve the prognosis for these patients and reduce treatment costs.
\end{abstract}

Key words

Metabolic disorders $\bullet$ Chronic kidney failure $\bullet$ Dialysis $\bullet$ Cardiovascular disease

\section{Introduction}

Chronic kidney disease (CKD) is a very real and growing problem, as indicated by demographic trends. The total number of treated patients has markedly increased during the last 30 years, and CKD currently affects approximately 19 millions of adult Americans, with an incidence that is increasing rapidly (Snyder and Pendergraph 2005). This trend is caused by a growing percentage of elderly people in the population as well as by technical progress and broader availability of dialysis therapy. An increasing number of diabetic patients is also an important factor.

CKD is characterized by progressive deterioration of kidney function, which develops eventually into a terminal stage of chronic kidney failure (CKF). CKF has traditionally been categorized as mild, moderate, or severe. Other poorly defined terms like uremia and end-stage renal disease (ESRD) have commonly been applied. During the last few years, an international consensus has emerged categorizing CKF into five stages according to the glomerular filtration rate (GFR) and presence of signs of kidney damage: stage 1: GFR $>90 \mathrm{ml} / \mathrm{min}$ and signs of kidney damage, stage 2: GFR $=60-89 \mathrm{ml} / \mathrm{min}$ and signs of kidney damage, stage 3: $\mathrm{GFR}=30-59 \mathrm{ml} / \mathrm{min}$, stage $4: \mathrm{GFR}=15-29 \mathrm{ml} / \mathrm{min}$, and stage 5: GFR $<15 \mathrm{ml} / \mathrm{min}$ (Levey et al. 2005).

Stage 5 represents the total inability of kidneys to maintain homeostasis, and this metabolic state is incompatible with life. Thus, at this stage, it is necessary 
to use methods that substitute for kidney function to ensure patient survival; these methods include peritoneal dialysis, hemodialysis, and other extracorporeal purifying procedures, or kidney transplantation.

$\mathrm{CKF}$ is associated with many kinds of metabolic changes caused by the kidney disease and also attributable to dialysis treatment. Phenomena such as accumulation or deficit of various substances and dysregulation of metabolic pathways combine in the pathogenesis of these changes (Cibulka et al. 2005). In the process of accumulation, decreased urinary excretion plays a crucial role and leads to retention of metabolites in the organism (e.g. creatinine, urea, electrolytes, water). The increased formation of metabolites through catabolic processes and alternative metabolic pathways also exerts an influence. Regular dialysis treatment partly decreases this accumulation, but cannot avert the overall deficit.

This deficit of some important substances in CKF can be caused by deficient intake in the diet, impaired intestinal absorption, or increased losses during dialysis sessions. Disturbed synthesis of some crucial metabolic regulators (e.g. erythropoietin, active vitamin D) in kidneys also plays an important role.

All of the above mentioned factors lead to many serious complications for CKD patients during the course of predialysis and dialysis. All accelerate the development of atherosclerosis, malnutritioninflammation complex syndrome (MICS), anemia, hyperparathyroidism, and other serious problems that markedly affect prognosis and the quality of life of patients with CKF (Lindner et al. 1974, Durak et al. 1994, Silver 2000, Cibulka et al. 2005).

\section{Acid-base balance}

Acid-base disorder is commonly observed in the course of CKF. Metabolic acidosis is noted in a majority of patients when GFR decreases to less than 20 to $25 \%$ of normal. The degree of acidosis approximately correlates with the severity of CKF and usually is more severe at a lower GFR. Metabolic acidosis can be of the high-anion-gap type, although the anion gap can be normal or only moderately increased even with stages 4 or 5 of CKF (Kraut and Kurtz 2005). In mild chronic renal insufficiency, metabolic acidosis is the result of a reduced ability to reabsorb bicarbonate, to excrete ammonia, and to eliminate titratable acid excretion (hyperchloremic, normal anion gap acidosis). In more severe renal insufficiency, organic and other conjugate anions of acids (nonvolatile acids) cannot be sufficiently excreted, and elevated anion gap acidosis appears (Kovacic et al. 2003). Acidosis resulting from advanced renal insufficiency is called uremic acidosis. The level of GFR at which uremic acidosis develops varies depending on a multiplicity of factors. Endogenous acid production is an important factor, which in turn depends on the diet. Ingestion of vegetables and fruits results in net production of alkali, and therefore increased ingestion of these foods will tend to delay the appearance of metabolic acidosis in chronic renal failure. Diuretic therapy and hypokalemia, which tend to stimulate ammonia production, may also delay the development of acidosis. The etiology of the renal disease also plays a role. In predominantly tubulointerstitial renal diseases, acidosis tends to develop earlier in the course of renal insufficiency than in predominantly glomerular diseases. In general, metabolic acidosis is rare when the GFR is greater than 20-25 ml/min (Oh et al. 2004).

Several adverse consequences have been associated with uremic acidosis, including muscle wasting, bone disease, abnormalities in growth hormone and thyroid hormone secretion, impaired insulin sensitivity, and exacerbation of beta-2 microglobulin accumulation (Kraut and Kurtz 2005). Other complications include negative nitrogen balance, anorexia, fatigue, impaired function of the cardiovascular system, hyperkalemia, and altered gluconeogenesis and triglyceride metabolism (Kovacic et al. 2003).

Therapy of uremic acidosis should aim to obtain a serum bicarbonate level as close to normal as possible (i.e. $22-26 \mathrm{mmol} / \mathrm{l}$ ). The best way to initiate therapy is with oral sodium bicarbonate ( 1 tablet three times a day) and to increase the dosage as necessary. The usual tablet of $650 \mathrm{mg}$ of sodium bicarbonate contains $7.5 \mathrm{mmol}$ of alkali $\left(\mathrm{HCO}_{3}^{-}\right.$ions). Occasionally, patients experience gastric discomfort with sodium bicarbonate and may use Shohl's solution (a mixture of sodium citrate and citric acid). In dialysis patients, treatment of acidosis relies on the gain of alkali from the dialysate either as bicarbonate in hemodialysis or as lactate in peritoneal dialysis ( $\mathrm{Oh}$ et al. 2004).

\section{Protein metabolism}

A strict low-protein diet can have a negative effect on nitrogen balance in the predialysis period. A safe low-protein diet should contain a minimum $0.6 \mathrm{~g}$ of protein $/ \mathrm{kg} /$ day. Disorders in protein metabolism in the dialysis period are usually caused by combined (protein and energy) malnutrition that can be termed uremic 
malnutrition. It is present in approximately 20-50\% of patients on dialysis and is characterized by insidious loss of somatic protein stores (reflected in lean body mass and serum creatinine) and visceral protein concentrations (reflected in serum albumin and prealbumin concentrations) (Ikizler 2004). Urinary losses of protein and losses of amino acids during a dialysis session may also play a role. Metabolic acidosis is an important factor that markedly contributes to negative nitrogen and total body protein balance in CKF (Kovacic et al. 2003, Mehrotra et al. 2003). It has been demonstrated that the presence of uremic malnutrition increases mortality and morbidity in chronic dialysis patients (Kopple 1994, Ikizler et al. 1999). It is very often combined with a chronic inflammation state in the malnutritioninflammation complex syndrome (MICS) (KalantarZadeh et al. 2003).

\section{Carbohydrate metabolism}

Disorders of carbohydrate metabolism are also very frequent in CKD. Diabetics represent about $35 \%$ of all patients on dialysis therapy. Furthermore, non-diabetic CKD patients often have glucose intolerance, probably because of peripheral insulin resistance (Alvestrand 1997). Insulin resistance is primarily detectable when the GFR is below $50 \mathrm{ml} / \mathrm{min}$. Reduced insulin-mediated nonoxidative glucose disposal is the most evident defect of glucose metabolism, but impairments of glucose oxidation, the defective suppression of endogenous glucose production, and abnormal insulin secretion also contribute to uremic glucose intolerance (Rigalleau and Gin 2005). Accumulating nitrogenous uremic toxins seem to be the dominant cause of a specific defect in insulin action, and identification of these toxins is progressing, particularly in the field of carbamoylated amino acids. The consequences of $\mathrm{CKF}$, such as exercise intolerance, anemia, metabolic acidosis, secondary hyperparathyroidism, or vitamin D deficiency, also indirectly play a role (Rasic-Milutinovic et al. 2000, Rigalleau and Gin 2005). It has been reported that insulin resistance may be related to arterial hypertension (Ferrannini et al. 1987) and may contribute to high cardiovascular morbidity and mortality in patients with CKF (Shoji et al. 2001, Shinohara et al. 2002). The underlying mechanism can be an impaired synthesis of nitric oxide (NO) in the endothelium of patients with CKD. It was reported that appropriately functioning endothelial NO synthase (eNOS) is important for the control not only of arterial pressure but also of glucose and lipid homeostasis (Duplain et al. 2001).

\section{Lipid metabolism}

Serum triglycerides (TG) are elevated in CKF because of enhanced production of TG-rich lipoproteins such as very-low-density lipoproteins (VLDL) in the liver (Attman et al. 1993) and also because of dysfunction of TG degradation resulting from insufficient mitochondrial beta-oxidation of fatty acids. It can be caused by a deficit of L-carnitine, which is frequently present, especially in hemodialysis patients (Guarnieri et al. 1992, Cibulka et al. 2005). Hyperinsulinemia is the main factor increasing synthesis of TG and also directly decreasing the activity of lipoprotein lipase. The most prominent changes in lipid metabolism found in many patients with CKF are increased serum TG levels and low levels of high-density lipoprotein (HDL) cholesterol. Low-density lipoprotein (LDL) cholesterol levels are often normal, but the cholesterol may originate from the atherogenic small and dense LDL subclass. The apolipoprotein B-containing part of the lipoprotein may undergo modifications (peptide modification of the enzymatic and advanced glycation end-products, oxidation or glycation). Modifications contribute to impaired LDL receptormediated clearance from the plasma and promote prolonged circulation. HDL particles are structurally altered during the states of inflammation. The contribution of this complex atherogenic form of dyslipidemia to cardiovascular disease (CVD) in patients with renal disease is at present not clear.

Some studies have reported negative results regarding the predictive power of serum lipids for the development of CVD (Wanner and Krane 2002). Recent findings have suggested that the development of MICS is responsible for this phenomenon. Because MICS leads to a low body mass index, hypocholesterolemia, hypocreatininemia, hypohomocysteinemia, and other manifestations, a reverse epidemiology of traditional cardiovascular risk factors occurs in CKF. Therefore, hypercholesterolemia, obesity, and increased blood levels of creatinine and homocysteine appear to be protective and paradoxically associated with a better outcome in patients with CKF (Kalantar-Zadeh et al. 2003, 2005).

It is well known that HDL cholesterol levels are inversely correlated with the risk of atherosclerosis. In addition to its role in reverse cholesterol transport, HDL has the ability to protect LDL particles against oxidation. The underlying mechanism by which HDL inhibits LDL oxidation is partly enzymatic. There is increasing 
evidence that paraoxonase 1 (PON1) could be involved in this process (Mackness et al. 1993). It was proved that serum PON1 activity is reduced in CKF patients. The possible causes can include reduced HDL levels, altered HDL subfraction distribution, reduced PON1 concentration and different PON1 phenotype distributions. Another possible explanation could be that PON1 activity is inhibited in an uremic environment. Generally, reduced serum PON1 activity could also contribute to the accelerated development of atherosclerosis in CKF patients (Dirican et al. 2004).

Lipoprotein(a) $[\mathrm{Lp}(\mathrm{a})]$ has been identified as an independent risk factor for atherosclerotic CVD. It was found to be consistently elevated in a considerable proportion of CKD patients. Plasma concentrations of Lp(a) are highly hereditable and mainly determined by a size polymorphism of apolipoprotein(a) [Apo(a)]. It has been demonstrated that the low-molecular-weight Apo(a) phenotype independently predicted coronary artery disease occurrence in a cohort of 440 unselected hemodialysis (HD) patients in a prospective study over five years (Kronenberg et al. 1999). It has been suggested that the Apo(a) size and the Lp(a) plasma concentration may play a synergistic role in advanced atherosclerosis.

Because kidneys perform important hormonal functions, there are also some serious complications associated with a lack of important metabolic hormonal regulators in the course of CKF. The major problems are primarily renal anemia and renal bone disease (renal osteodystrophy).

\section{Renal anemia}

Renal anemia, which is often associated with fatigue and cognitive and sexual dysfunction, has a significant impact on the quality of life of patients with CKF. Anemia has also been identified as an important etiologic factor in the development of left ventricular hypertrophy, an independent risk factor for heart failure and a predictor of mortality in HD patients (Golper et al. 2003). The major cause of renal anemia in CKF is an inadequate production of the glycoprotein hormone erythropoietin (EPO) because of a reduction in functional kidney parenchyma (Santoro 2002). Furthermore, free radicals elicited from leukocytes by their contact with the dialysis membrane cause hemolysis with consecutive anemia in CKF patients on extracorporeal renal replacement therapy (Eiselt et al. 1999).

There are numerous other metabolic derangements associated with uremia that can affect the production and survival of red blood cells (e.g. some uremic toxins, parathormone, protein malnutrition) (Eschbach and Adamson 1985, Golper et al. 2003). The introduction of recombinant human EPO (rHuEPO) has revolutionized the treatment of anemia in CKF. The vast majority of patients respond well to treatment, but 5-10\% of patients show some resistance to rHuEPO, the most common causes of which are considered due to iron deficiency (Santoro 2002) and the development of MICS (Kalantar-Zadeh et al. 2003). The EPO hyporesponsiveness can further worsen symptoms that decrease the quality of life, such as an intolerance of physical work, deterioration of cognitive functions, anorexia, insomnia, or depression. These problems are partly related to the deficit of L-carnitine in HD patients (dialysis-related carnitine disorder). This disorder is a functional metabolic deficiency common in chronic HD patients and can have a negative impact on erythrocyte production and survival. Laboratory studies examining the influence of carnitine on red blood cell function and clinical trials in HD patients support the use of L-carnitine in the setting of rHuEPO hyporesponsiveness (Golper et al. 2003).

\section{Renal osteodystrophy}

Renal osteodystrophy, which is the term used to describe the skeletal abnormalities of many CKD patients, is a multifactorial disorder of bone remodeling. It encompasses a heterogeneous group of disorders from states of high bone turnover to states of low bone turnover. High-turnover bone disease or osteitis fibrosa represents the manifestations of secondary hyperparathyroidism (SHPT) on bone. Low bone turnover syndromes are represented by the increasingly prevalent adynamic bone or less commonly, by osteomalacia. These disorders may occur in combination or alternately, each may predominate in any given patient (Gonzalez and Martin 2001). The most important factor, which is probably responsible for SHPT development, is due to a deficit of active vitamin D (calcitriol). Diseased kidneys cannot sufficiently hydroxylate 25-hydroxycholecalciferol, which is a precursor of calcitriol. The deficit of calcitriol causes an inadequate absorption of calcium in the small intestine, with resulting hypocalcemia. Retention of inorganic phosphate may deteriorate this situation because phosphates impair the activity of 1- $\alpha$-hydroxylase even more. Long-lasting hypocalcemia and coincidental hyperphosphatemia lead to the stimulation of parathyroid glands and subsequent SHPT, which causes decalcification of bones. Chronic 
metabolic acidosis intensifies this harmful process (Kraut and Kurtz 2005). All of these factors are closely interrelated, and while one or more of them may predominate in a particular patient during the course of CKF, much overlap occurs (Gonzalez and Martin 2001). Moreover, hyperphosphatemia has been recognized as an important risk factor for CVD mortality in patients with CKF. It is a direct cause of vascular calcification (Giachelli et al. 2005, Lund et al. 2006).

The treatment of vitamin D deficiency when present in CKD patients is warranted since such therapy may reduce or prevent SHPT in the early stages of CKD. In patients with CKD and GFR of 20-60 $\mathrm{ml} / \mathrm{min}$, nutritional vitamin $\mathrm{D}$ deficiency and insufficiency can both be prevented by supplementation with vitamin $\mathrm{D}_{2}$ (ergocalciferol) or vitamin $\mathrm{D}_{3}$ (cholecalciferol). The recommended daily allowance in individuals over 60 years is $800 \mathrm{IU}$, and for younger adults $400 \mathrm{IU}$. In patients in stage 5 of CKF and in those on dialysis, the value of supplementation is less certain; although in dialysis-dependent patients, high doses of ergocalciferol or 25-hydroxycholecalciferol can raise the serum levels of calcitriol. Calcitriol or other 1- $\alpha$-hydroxylated vitamin D sterols should not be used to treat vitamin D deficiency (National Kidney Foundation 2004).

\section{Cardiovascular disease}

CVD is the leading cause of death in patients with CKF. For every registry reporting national dialysis data in Europe, the U.S., Japan, and elsewhere, about $50 \%$ of deaths are attributed to CVD (Foley et al. 1998). In comparison with the general population, dialysis patients have a more than 20-fold increased risk of cardiovascular death (Levey and Eknoyan 1999). A majority of these deaths are related to vascular occlusive disease with associated myocardial infarction, cerebrovascular strokes, and ischemic events of the limbs. Additionally, patients with CKD exhibit evidence of early and exaggerated vascular and cardiac remodeling (arteriosclerosis and left ventricular hypertrophy). The risk of CVD and associated mortality increases in proportion to the decrease in GFR. It is significantly higher if GFR has fallen below approximately $75 \mathrm{ml} / \mathrm{min}$. The evidence suggests that the damage is already far progressed when patients reach ESRD; thus, effective intervention must be started much earlier (Diaz-Buxo and Woods 2006). Patients with albuminuria and normal GFR are also at increased risk (Go et al. 2004). Evaluation for traditional risk factors, including high lipid levels, hypertension, smoking, and sedentary lifestyle, is essential (Snyder and Pendergraph 2005). The KDOQI (Kidney Disease Outcomes Quality Initiative) recommended a blood pressure goal of 130/80 $\mathrm{mm} \mathrm{Hg}$ in patients with normal urinary albumin concentrations, and a blood pressure goal of $125 / 75 \mathrm{~mm} \mathrm{Hg}$ in patients with excretion of more than $1 \mathrm{~g}$ of protein $/ 24 \mathrm{~h}$ (National Kidney Foundation 2002).

The KDOQI guidelines on managing dyslipidemias in CKD patients recommend an LDL cholesterol goal of less than $100 \mathrm{mg} / \mathrm{dl}(2.60 \mathrm{mmol} / \mathrm{l})$ (National Kidney Foundation 2006). However, as mentioned above, some CKD patients with the lowest cholesterol levels are the most likely to die of CVD because low levels of cholesterol are associated with nontraditional cardiac risk factors of malnutrition and are markers of MICS (Liu et al. 2004, Kalantar-Zadeh et al. 2005). Additional cardiac risk factors specific to CKF include volume overload, hyperparathyroidism, uremia, anemia, endothelial dysfunction, and, especially in HD patients, oxidative stress (Eiselt et al. 1999).

\section{Oxidative stress}

Oxidative stress is the state in which the production of reactive oxygen species (ROS) exceeds the capacity of the antioxidant defense system in cells and tissues. ROS are free radicals, highly reactive substances with an unpaired electron in the outer orbital, and other related reactive compounds (such as hydrogen peroxide and hypochlorous acid) that can attack lipids, proteins, and nucleic acids and alter the structure and function of these macromolecules (Klaunig et al. 1998, Eiselt et al. 1999). Specifically, LDL particles are damaged by excessive oxidation and consequently are not recognized by cell LDL receptors. They are subsequently accumulated in the blood in higher amounts and penetrate the vascular walls. This mechanism is probably the basis of atherosclerotic lesions. Oxidative stress threatens HD patients with serious clinical complications (e.g. accelerated atherosclerosis, amyloidosis, hemolysis, and the development of $\mathrm{f}$ chronic inflammation). Free radicals originate from leucocytes, which are activated during the contact with the dialysis membrane, and also from erythrocyte iron released as a consequence of hemolysis (Eiselt et al. 1999). Intravenous administration of iron often used as a supplement of EPO treatment can also contribute to oxidative stress, increasing free radical production by the so-called Fenton reaction (Lim et al. 1999). Co-administration of ascorbic acid with the goal of 
mobilizing iron stores further stimulates free radical formation, possibly by reduction of $\mathrm{Fe}$ (III) ions to more dangerous Fe(II) compounds (Eiselt et al. 2006).

\section{Dialysis-related amyloidosis}

Dialysis-related amyloidosis (DRA) is a frequent complication of CKF and long-term renal replacement therapy. Beta-2 microglobulin is a major constituent of amyloid fibrils in DRA. Amyloid deposition mainly involves bone and joint structures, presenting as carpal tunnel syndrome, destructive arthropathy, and subchondral bone erosions and cysts. The molecular pathogenesis of this complication remains unknown. Recent studies, however, have suggested a pathogenic role of a new modification of beta- 2 microglobulin in amyloid fibrils. Increased carbonyl compounds derived from autoxidation of both carbohydrates and lipids modify proteins in uremia, leading to augmentation of advanced glycation end-products and advanced lipoxidation end-product production. Thus, uremia might be a state of carbonyl overload with potentially damaging proteins (carbonyl stress) (Miyata et al. 1999).

\section{Hyperhomocysteinemia and endothelial dysfunction}

Hyperhomocysteinemia is present in the majority of CKF patients. They have plasma concentration of homocysteine (Hcy) elevated 3 to 4 times above normal (Suliman et al. 2001). The causes are still not clear, but the possibilities include defective renal or extrarenal metabolism as a result of uremic toxicity (Perna et al. 2004). In the general population, hyperhomocysteinemia is considered to be an independent risk factor for the development of CVD (Racek et al. 2005). As mentioned above, reverse epidemiology of traditional cardiovascular risk factors can occur in CKF, so that increased Hcy levels appear to be paradoxically associated with a better clinical outcome. The development of MICS is responsible for this phenomenon (Kalantar-Zadeh et al. 2005). Plasma Hcy concentration is higher in CRF patients with normal nutritional status than in malnourished patients. Plasma Hcy was inversely correlated with subjective global nutritional assessment and positively correlated with serum albumin and protein intake. Thus, serum albumin concentration is a strong determinant of plasma Hcy in patients with CRF, which may contribute to the lower Hcy levels in malnourished patients (Suliman et al. 2001).

On the other hand, the toxicity of Hcy results from the structural modification of proteins and DNA. Disruption of DNA methylation has been demonstrated to occur as a result of hyperhomocysteinemia and is associated with vascular damage (Perna et al. 2005). Hcy could be a principal candidate for endothelial dysfunction in patients with CRF. Hyperhomocysteinemia may impair endothelial function by the generation of oxygen species and decreased NO bioavailability. Normal endothelium is characterized by an intact and appropriately functioning eNOS-NO system in which eNOS is constitutively active and constantly generates small amounts of NO (Nedeljkovic et al. 2003). NO mediates normal endothelial and vessel wall functions including antithrombosis, endothelial permselectivity, and vasomotor tone. In addition, NO suppresses cellular proliferation (including vascular smooth muscle cells) and has a quenching effect on inflammation. The function of the eNOS-NO system is impaired in patients with CKD (Kone 1997). However, the precise mechanisms underlying the link between hyperhomocysteinemia and impaired endothelial function in CRF remain unclear (Takamitsu and Nakanishi 2001). Some authors propose that accumulation of asymmetric dimethylarginine (ADMA), an endogenous inhibitor of NO synthase, is the missing connecting link. Hcy is produced during ADMA synthesis and can alter ADMA catabolism mainly by inhibiting dimethylarginine dimethylaminohydrolase (Dayal and Lentz 2005). ADMA levels are elevated in CKD patients, and ADMA is a candidate as a new uremic toxin (De Deyn et al. 2003). In some studies, an increased level of ADMA has been identified as an independent predictor of mortality in patients with CKD (Ravani et al. 2005). In any case, modulation of endothelial function in CRF may offer a novel strategy to reduce CVD.

Thus, it is necessary to emphasize the necessity of searching actively for CKD. Unfortunately, it is often overlooked in its earliest, most treatable stages. Guidelines from the National Kidney Foundation's KDOQI recommend estimating GFR and screening for albuminuria in patients with risk factors for CKD, including diabetes, hypertension, systemic illnesses, age greater than 60 years, and family history of CKD. When CKD is detected, an attempt should be made to identify and treat the underlying conditions as well as the secondary abnormalities. These goals include slowing disease progression, detecting and treating complications, and managing cardiovascular risk factors. Suitable treatment also includes attention to the influence of elevated blood pressure, malnutrition, anemia, 
hyperparathyroidism, insulin resistance, disorders of lipid metabolism, and acid-base balance. At the same time, it is necessary to continue research projects focused on other areas that may uncover new aspects of cardiometabolic risk and its influence in CKD patients. These areas include the development of MICS, management of oxidative stress, and endothelium protection. Clearly, progress in management of CVD in patients with CKD will require collaboration with experts in the research and treatment of vascular disease.

\section{Conclusions}

Chronic kidney disease leading to chronic kidney failure is an urgent medical problem in the context of demographic trends. In addition to the basic kidney disease, many metabolic disorders develop in the course of CKF. Particularly, patients in the terminal stage of CKF are endangered. Regular dialysis treatment decreases the accumulation of metabolites; however, it contributes to a deficit of some important metabolic regulators and to the development of a chronic inflammation state. These factors can lead to serious secondary complications in CKF, including atherosclerosis and related cardiovascular disease, malnutrition, anemia, renal bone disease, and other problems. These complications markedly and negatively affect the prognosis and quality of life of patients with CKF and increase costs for their treatment. The prognosis of CKD patients can be improved if kidney disease is diagnosed early and properly cured, including secondary complications. Appropriate treatment encompasses consistent control of blood pressure, prevention of malnutrition, anemia, and hyperparathyroidism, and treatment of metabolic disorders. It is necessary to search actively for kidney disease and to develop new therapeutic methods to improve the quality of life of CKD patients. At the same time, we must try to reduce economic costs connected with the treatment.

\section{Acknowledgements}

This work was supported by the research project MSM 0021620819.

\section{References}

ALVESTRAND A: Carbohydrate and insulin metabolism in renal failure. Kidney Int Suppl 62: S48-S52, 1997.

ATTMAN PO, SAMUELSSON O, ALAUPOVIC P: Lipoprotein metabolism and renal failure. Am J Kidney Dis 21: 573-592, 1993.

CIBULKA R, RACEK J, VESELA E: The importance of L-carnitine in patients with chronic renal failure treated with hemodialysis (in Czech). Vnitr Lek 51: 1108-1113, 2005.

DAYAL S, LENTZ SR: ADMA and hyperhomocysteinemia. Vasc Med 10 (Suppl 1): S27-S33, 2005.

DE DEYN PP, VANHOLDER R, D'HOOGE R: Nitric oxide in uremia: Effects of several potentially toxic guanidino compounds. Kidney Int 63 (Suppl 84): S25-S28, 2003.

DIAZ-BUXO JA, WOODS HF: Protecting the endothelium: A new focus for management of chronic kidney disease. Hemodial Int 10: 42-48, 2006.

DIRICAN M, AKCA R, SARANDOL E, DILEK K: Serum paraoxonase activity in uremic predialysis and hemodialysis patients. J Nephrol 17: 813-818, 2004.

DUPLAIN H, BURCELIN R, SARTORI C, COOK S, EGLI M, LEPORI M, VOLLENWEIDER P, PEDRAZZINI T, NICOD P, THORENS B, SCHERRER U: Insulin resistance, hyperlipidemia and hypertension in mice lacking endothelial nitric oxide synthase. Circulation 104: 342-345, 2001.

DURAK I, AKYOL O, BASESME E, CANBOLAT O, KAVUTCU M: Reduced erythrocyte defense mechanisms against free radical toxicity in patients with chronic renal failure. Nephron 66: 76-80, 1994.

EISELT J, RACEK J, OPATRNÝ K Jr: Free radicals and extracorporeal renal replacement therapy (in Czech). Vnitr Lek 45: 319-324, 1999.

EISELT J, RACEK J, OPATRNÝ K Jr, TREFIL L, STEHLÍK P: The effect of intravenous iron on oxidative stress in hemodialysis patients at various levels of vitamin C. Blood Purif 24: 531-537, 2006.

EISELT J, RACEK J, OPATRNÝ K Jr: Free radicals and extracorporeal renal replacement therapy. Vnitr Lek 45: 319 $324,1999$.

ESCHBACH JW, ADAMSON JW: Anemia of end-stage renal disease. Kidney Int 28: 1-5, 1985. 
FERRANNINI E, BUZZIGOLI G, BONADONNA R, GIORICO MA, OLEGGINI M, GRAZIADEI L, PEDRINELLI R, BRANDI L, BEVILACQUA S: Insulin resistance in essential hypertension. N Engl J Med 317: 350-357, 1987.

FOLEY RN, PARFREY PS, SARNAK MJ: Clinical epidemiology of cardiovascular disease in chronic renal disease. Am J Kidney Dis 32 (Suppl 3): S112-S119, 1998.

GIACHELLI CM, SPEER MY, LI X, RAJACHAR RM, YANG H: Regulation of vascular calcification: roles of phosphate and osteopontin. Circ Res 96: 717-722, 2005.

GO AS, CHERTOW GM, FAN D, MCCULLOCH CE, HSU CY: Chronic kidney disease and the risk of death, cardiovascular events, and hospitalization. N Engl J Med 351: 1296-1305, 2004.

GOLPER TA, GORAL S, BECKER BN, LANGMAN CB: L-carnitine treatment of anemia. Am J Kidney Dis 41 (Suppl 4): S27-S34, 2003.

GONZALEZ EA, MARTIN KJ: Renal osteodystrophy. Rev Endocr Metab Disord 2: 187-193, 2001.

GUARNIERI G, FONDA M, SITULIN R, VASILE A, TOIGO G, CATTIN L: Effects of L-carnitine supplementation in the dialysate on serum lipoprotein composition of hemodialysis patients. Contrib Nephrol 98: 36-43, 1992.

IKIZLER TA: Protein and energy: recommended intake and nutrient supplementation in chronic dialysis patients. Semin Dial 17: 471-478, 2004.

IKIZLER TA, WINDGARD RL, HARVELL J, SHYR Y, HAKIM RM: Association of morbidity with markers of nutrition and inflammation in chronic hemodialysis patients: a prospective study. Kidney Int 55: 1945-1951, 1999.

KALANTAR-ZADEH K, IKIZLER TA, BLOCK G, AVRAM MM, KOPPLE JD: Malnutrition-inflammation complex syndrome in dialysis patients: causes and consequences. Am J Kidney Dis 42: 864-881, 2003.

KALANTAR-ZADEH K, STENVINKEL P, BROSS R, KHAWAR OS, RAMMOHAN M, COLMAN S, BENNER D: Kidney insufficiency and nutrient-based modulation of inflammation. Curr Opin Clin Nutr Metab Care 8: 388396, 2005.

KLAUNIG JE, XU Y, ISENBERG JS, BACHOWSKI S, KOLAJA KL, JIANG J, STEVENSON DE, WALBORG EF Jr: The role of oxidative stress in chemical carcinogenesis. Environ Health Perspect 106 (Suppl 1): 289-295, 1998.

KONE BC: Nitric oxide in renal health and disease. Am J Kidney Dis 30: 311-333, 1997.

KOPPLE JD: Effect of nutrition on morbidity and mortality in maintenance dialysis patients. Am J Kidney Dis 24: 1002-1009, 1994.

KOVACIC V, ROGULJIC L, KOVACIC V: Metabolic acidosis of chronically hemodialyzed patients. Am J Nephrol 23: 158-164, 2003.

KRAUT JA, KURTZ I: Metabolic acidosis of CKD: diagnosis, clinical characteristics, and treatment. Am J Kidney Dis 45: 978-993, 2005.

KRONENBERG F, NEYER U, LHOTTA K, TRENKWALDER E, AUINGER M, PRIBASNIG A, MEISL T, KONIG P, DIEPLINGER H: The low molecular weight apo(a) phenotype is an independent predictor for coronary artery disease in hemodialysis patients: a prospective follow-up. J Am Soc Nephrol 10: 1027-1036, 1999.

LEVEY AS, EKNOYAN G: Cardiovascular disease in chronic renal disease. Nephrol Dial Transplant 14: 828-833, 1999.

LEVEY AS, ECKARDT KU, TSUKAMOTO Y, LEVIN A, CORESH J, ROSSERT J, ZEEUW D, HOSTETTER TH, LAMEIRE N, EKNOYAN G: Definition and classification of chronic kidney disease: a position statement from Kidney Disease: Improving Global Outcomes (KDIGO). Kidney Int 67: 2089-2100, 2005.

LIM PS, WEI YH, YU YL, KHO B: Enhanced oxidative stress in haemodialysis patients receiving intravenous iron therapy. Nephrol Dial Transplant 14: 2680-2687, 1999.

LINDNER A, CHARRA B, SHERRARD DJ, SCRIBNER BH: Accelerated atherosclerosis in prolonged maintenance hemodialysis. N Engl J Med 290: 697-701, 1974.

LIU Y, CORESH J, EUSTACE JA, LONGENECKER JC, JAAR B, FINK NE, TRACY RP, POWE NR, KLAG MJ: Association between cholesterol level and mortality in dialysis patients: role of inflammation and malnutrition. JAMA 291: 451-459, 2004.

LUND RJ, DAVIES MR, SURESH M, HRUSKA KA: New discoveries in the pathogenesis of renal osteodystrophy. J Bone Miner Metab 24: 169-171, 2006. 
MACKNESS MI, ARROL S, ABBOTT CA, DURRINGTON PN: Protection of low-density lipoprotein against oxidative modification by high density lipoprotein associated paraoxonase. Atherosclerosis 104: 129-135, 1993.

MEHROTRA R, KOPPLE JD, WOLFSON M: Metabolic acidosis in maintenance dialysis patients: clinical considerations. Kidney Int 64 (Suppl 88): S13-S25, 2003.

MIYATA T, INAGI R, KUROKAWA K: Diagnosis, pathogenesis, and treatment of dialysis-related amyloidosis. Miner Electrolyte Metab 25: 114-117, 1999.

NATIONAL KIDNEY FOUNDATION: K/DOQI, clinical practice guidelines for chronic kidney disease: evaluation, classification and stratification. Am J Kidney Dis 39 (2 Suppl 1): S1-S266, 2002. http://www.kidney.org/ professionals/kdoqi/guidelines_ckd/toc.htm.

NATIONAL KIDNEY FOUNDATION: K/DOQI, clinical practice guidelines for bone metabolism and disease in chronic kidney disease, guideline 7. 2004. http://www.kidney.org/professionals/kdoqi/ guidelines_bone/Guide7.htm.

NATIONAL KIDNEY FOUNDATION: K/DOQI, clinical practice guidelines for managing dyslipidemias in chronic kidney disease, part 3, guideline 4. 2006. http://www.kidney.org/professionals/kdoqi/guidelines_lipids/iii.htm.

NEDELJKOVIC ZS, GAKCE N, LOSCALZO J: Mechanisms of oxidative stress and vascular dysfunction. Postrad Med J 79: 195-199, 2003.

OH MS, URIBARRI J, WEINSTEIN J, SCHREIBER M, KAMEL KS, KRAUT JA, MADIAS NE, LASKI ME: What unique acid-base considerations exist in dialysis patients? Semin Dial 17: 351-364, 2004.

PERNA AF, INGROSSO D, SATTA E, LOMBARDI C, ACANFORA F, DE SANTO NG: Homocysteine metabolism in renal failure. Curr Opin Clin Nutr Metab Care 7: 53-57, 2004.

PERNA AF, CAPASSO R, LOMBARDI C, ACANFORA F, SATTA E, INGROSSO D: Hyperhomocysteinemia and macromolecule modifications in uremic patients. Clin Chem Lab Med 43: 1032-1038, 2005.

RACEK J, RUSŇÁKOVÁ H, TREFIL L, SIALA KK: The influence of folate and antioxidants on homocysteine levels and oxidative stress in patients with hyperlipidemia and hyperhomocysteinemia. Physiol Res 54: 87-95, 2005.

RASIC-MILUTINOVIC Z, PERUNICIC-PECKOVIC G, PLJESA S: Clinical significance and pathogenic mechanism of insulin resistance in chronic renal insufficiency (part II): pathogenic factors of insulin resistance in chronic renal insufficiency. Med Pregl 53: 159-163, 2000.

RAVANI P, TRIPEPI G, MALBERTI F, TESTA S, MALLAMACI F, ZOCCALI C: Asymmetrical dimethylarginine predicts progression to dialysis and death in patients with chronic kidney disease: a competing risks modeling approach. J Am Soc Nephrol 16: 2254-2256, 2005.

RIGALlEAU V, GIN H: Carbohydrate metabolism in uremia. Curr Opin Clin Nutr Metab Care 8: 463-869, 2005.

SANTORO A: Anemia in renal insufficiency. Rev Clin Exp Hematol Suppl 1: 12-20, 2002.

SHINOHARA K, SHOJI T, EMOTO M, TAHARA H, KOYAMA H, ISHIMURA E, MIKI T, TABATA T, NISHIZAWA Y: Insulin resistance as an independent predictor of cardiovascular mortality in patients with end-stage renal disease. J Am Soc Nephrol 13: 1894-1900, 2002.

SHOJI T, EMOTO M, SHINOHARA K, KAKIYA R, TSUJIMOTO Y, KISHIMOTO H, ISHIMURA E, TABATA T, NISHIZAWA Y: Diabetes mellitus, aortic stiffness, and cardiovascular mortality in end-stage renal disease. J Am Soc Nephrol 12: 2117-2124, 2001.

SILVER J: Molecular mechanisms of secondary hyperparathyroidism. Nephrol Dial Transplant 15: 2-7, 2000.

SNYDER S, PENDERGRAPH B: Detection and evaluation of chronic kidney disease. Am Fam Physician 72: 1723$1732,2005$.

SULIMAN ME, LINDHOLM B, BARANY P, BERGSTROM J: Hyperhomocysteinemia in chronic renal failure patients: relation to nutritional status and cardiovascular disease. Clin Chem Lab Med 39: 734-738, 2001.

TAKAMITSU Y, NAKANISHI T: Association of endothelial dysfunction with sulfur amino acid metabolism in chronic renal failure. Am J Kidney Dis 38 (Suppl 1): S95-S99, 2001.

WANNER C, KRANE V: Uremia-specific alterations in lipid metabolism. Blood Purif 20 (Suppl 1): 451-453, 2002.

\section{Corresponding author}

R. Cibulka, Charles University Hospital in Pilsen, Institute of Clinical Biochemistry and Hematology, Alej Svobody 80, 30460 Plzeň, Czech Republic. E-mail: cibulkar@fnplzen.cz 